\title{
FAN CULTURE E ESCRITA DE SI: DISCURSO, EMOÇÃO E IDENTIDADE
}

Fan culture and self-writing: Speech, emotion and identity

\author{
Demóstenes Dantas Vieira ${ }^{1}$ \\ Luan Talles de Araújo Brito ${ }^{2}$
}

Recebido em 15/05/2016; aceito em 10/06/2016

\begin{abstract}
Resumo: Este trabalho propõe a análise de um Diário de fã, plataforma colaborativa através da qual os fãs compartilham as suas emoções e sentimento de pertença inerentes a sua condição. Com base nos pressupostos teórico-metodológicos da Análise do Discurso, principalmente, as contribuições de Michel Foucault, objetivamos analisar a relação entre a escrita de si no ambiente virtual, emoção e identidade. Para tanto, propomos uma investigação que traz à baila a escrita de si como mecanismo de sacralização, através do qual os fãs realizam determinados ritos de adoração. Como aporte teórico, ressaltamos as contribuições de Coelho (1999), Rezende e Coelho (2010), Vieira (2015), Bauman (2005), Jenkins (1992/1999), Foucault (1992), Morin (1997), dentre outros. A análise aponta para formações discursivas nas quais perpassam o carisma, fascínio, desejo de fusão e de singularização dos fãs. Tais emoções podem ser entendidas como parte integrante do discurso dos fãs, constituindo-se, aqui, como corpus analítico em busca da identificação de traços de subjetividade e marcas identitárias.
\end{abstract}

Palavras-chave: Diário de fã; Escrita de si; Emoção; Identidade.

\begin{abstract}
This work proposes analysis of a Fan Diary, collaborative platform through the qua os Fans share as your emotions and Sense of belonging inherent your condition. As base nos theoretical methodological of Discourse Analysis, mainly as contributions from Michel Foucault, we aimed to analyze the relationship between the writing itself in the virtual environment, emotion and identity of the saf. To this end, we propose a Research Bringing into question the self-writing how mechanisms of sacredness, do through the qua fans materialize as your emotions. As a theoretical framework, we highlight as contributions of Coelho (1999), Rezende and Coelho (2010), Vieira (2015), Bauman (2005), Jenkins (1992/1999), Foucault (1992), Morin (1997), others of. The analysis points paragraph discursive formations in which pervade the charisma, fascination, desire fusion and individualization of saf. Such emotions can be understood as part of fans Member of speech, being-is, here, as analytical corpus in search of subjectivity traces identification and identitarias brands .
\end{abstract}

Key words : Fan Diary; Writing itself ; Emotion ; Identity.

\footnotetext{
${ }^{1}$ Mestre em Ciências Sociais e Humanas pela Universidade do Estado do Rio Grande do Norte - UERN; Especialista em Educação Pelas Faculdades Integradas de Patos - FIP; Especialista em Literatura e Ensino pelo Instituto Federal de Educação, Ciência e Tecnologia do Rio Grande do Norte - IFRN, onde também atua como professor permanente de Língua Portuguesa e Literatura Brasileira. E-mail: demostenes.vieira@ifrn.edu.br

${ }^{2}$ Doutorando e Mestre em Letras pela Universidade do Estado do Rio Grande do Norte - UERN; Graduado em letras pela Universidade Estadual da Paraíba - UEPB. E-mail: luantalles_tdb@hotmail.com
} 


\section{CONSIDERAÇÕES INICIAIS}

A expressão fan culture, utilizada por Jenkins (1999), tem sido bastante utilizada nos estudos da mídia, principalmente, nas pesquisas em torno da relação fã/ídolo e cultura de massa. De forma simplificada, ela significa cultura dos fãs e designa a participação do sujeito na produção, circulação e difusão de bens culturais em torno da relação fã/ídolo. A princípio, ela estava associada aos fã clubes em ambiente off-line, expandindo-se para as relações online. Nesse sentido, a expressão cultura de fãs se refere a uma rede de interações socioculturais, através da qual nascem produtos culturais diversos, inspirados nos ídolos e/ou objetos de culto e adoração.

A revolução tecnológica possibilitou a expansão dos fã clubes outrora territorializados e agora virtualmente globalizados. O ambiente virtual proporcionou a criação de plataformas colaborativas através das quais os fãs se organizam para compartilhar não só as suas produções culturais, como também a experiência de ser fã, angústias, desejos, emoções. Tais plataformas constituem-se como redes de sociabilidade em torno da relação fã/ídolo e desejo de fusão, inerente a sua condição de fã. As fanfics, fan pages, grupos do facebook, diários de fã, blogs, entre outros, constituem-se como espaços virtuais nos quais materializam-se as práticas culturais dos fãs. Neles, os fãs também escrevem sobre si mesmos, trazendo à baila enunciados através das quais se pode identificar traços de subjetividade e marcas de sua identidade.

Segundo Dorneles $(2008$, p. 217), tais redes de sociabilidade, estão associadas à transposição de dados da vida off-line para as relações sociais no ambiente virtual, por esse motivo, fala-se de "sujeito virtual transposto" e "sujeito virtual construído". A primeira expressão nos remete à mudança espacial do indivíduo transposto do espaço físico dito "real" para o ciberespaço, que, segundo Lévy (1999), caracteriza-se pela ruptura com as noções de tempo e espaço tradicionalmente utilizados nas Ciências Sociais e Humanas. Nesse novo contexto, ressignificamos a noção de tempo, visto que podemos interagir com pessoas em diversas partes do mundo, com fuso horários diferentes, além das trocas que podem se realizar tanto espontaneamente (através de chats, webconferências, etc.) como não instantaneamente (através de fóruns de discussão, comentários, e-mails etc.).

A segunda expressão usada por Dornelles (2008), "sujeito construído", nos remete às múltiplas possibilidades de construção e representação de si no ciberespaço, tanto pela imaginação simbólica, como escreve Durrand (1988), como pela própria representação dos 
diversos papéis sociais ${ }^{3}$ que exercemos nos diversos contextos de interação social em que agimos, seja como filho, pai, professor, aluno, fã, ídolo, amigo etc. Nesse sentido, o Diário de fã pode ser entendido como uma plataforma virtual por meio da qual os fãs escrevem sobre si, produzindo formações discursivas em que se materializam suas emoções.

Nesse sentido, torna-se relevante pensarmos a dinâmica da relação fã/ídolo no ambiente virtual, pois a fan culture é um fenômeno contemporâneo de grande influência nos processos de formação de subjetividades. Por conseguinte, entender o fã é compreender o poder e participação da mídia nos processos de subjetivação que perpassam o cotidiano e as redes sociais. Nesse contexto, indagamos, o que desejam os fãs? O que querem em troca por tamanho afeto e admiração? Qual a importância dos ídolos na construção de sua identidade? Essas perguntas nos conduziram a uma pesquisa cujo objetivo é entender como os fãs utilizam a escrita de si como mecanismo de sacralização, através do qual também perpassa a exteriorização de suas emoções nas quais podem ser percebidos traços de subjetividade e identidade inerentes à condição de fã. Para tanto, analisaremos materialidades discursivas de um Diário de fã promovido pelo Blog do Planeta, blog de uma casa noturna de Teresina - PI, conhecida por receber diversas celebridades.

\section{SOBRE A FÃ CULTURE E A CONSTRUÇÃO DA IDENTIDADE}

A fan culture compreende um fenômeno moderno e bastante complexo. Essa expressão tem ganhado espaço no meio acadêmico, principalmente, através das pesquisas do comunicólogo Henry Jenkins. Ela se refere às teias de significados que se configuram a partir da relação fã, ídolo e cultura de massa. Nesse sentido, entende-se que o corpus investigativo desse fenômeno é a figura do fã submerso na cultura midiática em que se faz presente a mediação de subjetividades a partir da Indústria Cultural.

A definição científica do vocábulo fã assume valor semântico ligado à figura de um ídolo, à sacralização do sujeito, dada a sua relação com o consumo, com as emoções e com o desejo de fusão (JENKINS, 1992). A cultura dos fãs e, por conseguinte, a sacralização de pessoas, produtos e marcas está ligada à revolução tecnológica, à globalização e a crescente fetichização da vida, dos ideais e padrões de felicidade impostos pela mídia e pelo capital.

\footnotetext{
${ }^{3}$ Expressão usada por Goffman (2011) na teoria das representações sociais, através da qual o autor constrói a interpretação de que a vida social é construída a partir de representações, cujo participante se projeta diante de outros performaticamente, como um ator diante de uma plateia.
} 
Conforme escreve Bussab (2004), não pode existir uma cultura de fãs se não existir uma cultura de massa. É esta última que constrói os modelos de adoração, produz exemplos de família, de felicidade, gênios do esporte, da música, da teledramaturgia, e incute no olhar das pessoas a necessidade de ser igual, de vestir-se, amar, ser feliz tão quanto os Olimpianos. Os ídolos apresentam-se, portanto, como seres sacralizados pelo consumo, pela mídia e pela Indústria Cultural, como deuses do Olimpo, cuja beleza e soberania devem ser veneradas (MORIN, 1997).

$\mathrm{Na}$ dinâmica desse afeto, se apresentam as fan pages (páginas de fãs) e o Diário de fã , que se configuram a partir da natureza híbrida do ciberespaço, de lugar indefinido, das diversas culturas que o permeiam, saberes e alteridade que possibilitam a troca de experiências, o compartilhamento da memória e construção de uma consciência coletiva (LÉVY, 2000).

Nesses sentido, os ídolos assumem um espaço bastante significativo no processo de formação de subjetividade na modernidade, constituindo-se como peça importante na construção da identidade dos fãs. Bauman (2005) escreve que o processo de formação identidades não é estático. Segundo ele, é através das relações com o outro que nossa identidade se constitui, apesar de que o que somos hoje pode não ser o que seremos amanhã. Nesse sentido, o sujeito está sempre se constituindo e sua identidade está, portanto, em constante transformação. Bauman (2005, p. 54) escreve que a constituição do sujeito (mais especificamente, sua identidade) se dá como em um quebra-cabeça "ao qual faltam muitas peças (e jamais se saberá quantas)". Como objeto de adoração, o ídolo torna-se mais que uma pessoa admirada, mas um indivíduo cujas ações, vestuário, concepções e modo de vida passam a ser imitados, tornando-se peça importante desse quebra cabeça.

O diário de fã , que aqui nos interessa em particular, é um espaço dado pela mídia, através do qual os fãs expressam os mais diversos sentimentos, expectativas e declarações de amor ao ídolo e, geralmente, está também relacionado a uma premiação dada ao fã mais cativante e sincero, aquele que emocione com as palavras. A sua organização traz à tona a necessidade de pertencimento dos fãs, a busca de um lugar no mundo em que seus sentimentos sejam valorizados, respeitados e, principalmente, compartilhados. O diário de fã , assim como as fan pages, apresentam-se como suporte através do qual se torna possível uma consciência coletiva centrada na fan culture, pois eles possibilitam aos fãs um "templo virtual" de adoração através dos quais os rituais de sacralização tornam-se possíveis.

É notório que nas relações virtuais, considera-se cada vez mais comum a exposição da vida pessoal, de atividades antes associadas ao habitus privado e familiar. No ambiente 
virtual, o sujeito inscreve e é inscrito pela linguagem, através da qual escreve sobre o seu estado emocional, as ações do cotidiano, sua localização espacial, aspectos da vida amorosa, profissional etc. O sujeito/fã encontra nas redes de organização virtual uma forma de expressarem o afeto socialmente marginalizado e, por meio das práticas discursivas, ele escreve sobre a sua identidade, sobre desejos e frustrações. A escrita de si apresenta-se, portanto, como um mecanismo de exteriorização da interioridade, ou seja, de exposição daquilo que lhe confere individualidade, ao mesmo tempo em que incorpora e internaliza um habitus $^{4}$ ligado a fan culture, conforme escreve Bourdieu (1990), internalizando aquilo que é lhe é exterior e social.

\section{A ESCRITA DE SI E AS EMOÇÕES}

Ao escrever sobre a escrita de si, Foucault (1992) nos remonta à tradição estoica, ao estoicismo, com o objetivo de analisar práticas de escrita que marcam traços de subjetividade, através de mecanismos e técnicas de escritas de si e da relação que os sujeitos estabelecem com outrem.

Foucault (1992) escreve sobre duas formas de escrita etopiética (escrita como treino de si): os hypomnemata e a correspondência. Pode-se entender os hypomnemata como cadernos pessoais utilizados como guias espirituais para o exercício da meditação. Tais cadernos estão muito próximos do Diário e do blog (principalmente na sua origem). Segundo Foucault (1992), nesses cadernos poderíamos encontrar textos diversos, como trechos de obras lidas pelo indivíduo, citações de obras diversas de caráter filosófico-reflexivo, diálogos que se tinha ouvido/participado etc. Tais fragmentos eram de grande importância para os exames de sua consciência e reflexões futuras sobre si e sobre o mundo (FOUCAULT, 1992). Nesse sentido, a escrita dos hypomnemata constituem-se veículos de subjetivação e compreensão de si-para-si, da busca de um conhecimento e verdade de si mesmo.

Já as correspondências, por sua vez, remetem a uma escrita de si-para-o-outro, mas que também possibilita, evidentemente, uma escrita pessoal. O remetente escreve, por definição, para o outro, com o objetivo primeiro de consolá-lo, exortá-lo e aconselhá-lo, oferecendo-lhe o que de si mesmo se diz, ou seja, de suas experiências (FOUCAULT, 1992).

\footnotetext{
${ }^{4} \mathrm{O}$ habitus representa um engendramento, a interiorização das estruturas sociais nas quais o indivíduo está inserido. Assim como em Elias (1993), em Bourdieu, o habitus pode ser compreendido como "disposições duráveis" e inconscientes, tendo em vista a sua relação com estruturas historicizadas (BOURDIEU, 1994, p. 60).
} 
Desse modo, a escrita de si dos fãs pode ser compreendida tanto no âmbito de uma escrita de si-para-si, como forma de expressão de sua subjetividade, de exteriorização dos desejos e afetos marginalizados, como também pode ser entendida como uma escrita de sipara-o-outro, pois é notório o desejo de singularizar-se através da escrita, pois ele expõe através das palavras a "necessidade" psíquica e social de sair do anonimato, de não ser só mais um no meio da multidão (COELHO, 1999).

Conforme comentários do Diário de fã " "Ser fã é não ter medo de dizer 'Ei eu sou fã dessa banda, eu sou fã dessa pessoa. E eu amo muito eles. Ser fã é torcer pra que seus ídolos sejam felizes ao lado de uma pessoa, mesmo essa pessoa não sendo você” (FÃ 01). A materialidade textual citada demonstra a aceitação da condição marginal do seu afeto, "não ter medo de dizer" que é fã de determinada banda ou pessoa nos remete a uma memória discursiva relacionada a diversos discursos sociais que marginalizam o sentimento dos fãs, conforme escreve um fã em outro depoimento "quem é fã de verdade sabe que é preciso amar e defender ele, não importa o que digam e o que aconteça. É tu ter a certeza de que daria a sua vida pela dele!" (FÃ 02). O enunciado "defender ele, não importa o que digam" denota a marginalização social desse afeto e a defesa de sua identidade. Defender seu ídolo, independente do estigma social, é reconhecer-se tão marginalizado quanto à própria relação fã/ídolo. Nesse sentido, o fã encontra-se inserido na situação descrita por Rezende e Coelho (2010), na qual se confrontam a necessidade de expressão do seu sentimento e o reconhecimento do estigma social a que é submetido o seu afeto.

É interessante lembrarmos que as redes em rede, neste caso, se constroem como forma de resistência social, seja através de fan pages ou diário de fã. A escrita de si-para-ooutro é evidente, uma vez que se escreve sobre o ídolo como se estivesse escrevendo para ele, e isso é fruto do desejo de singularização, que consiste numa tentativa de destacar-se no meio da multidão, pois o fã enamorado/fascinado deseja mais do que participar dos ritos de adoração aos olimpianos (MORIN, 1997), eles desejam ser correspondidos, desejam reciprocidade amorosa e, em alguns casos, sexual (COELHO, 1999). Isso é bastante evidente na materialidade que segue: “amo muiito o Pelanza, não é só amor de fã, enfim... espero que um dia pelo menos um abraço dele eu possa ganhar já que não posso ganhar um beijo na buchecha, e etc.” (FÃ 03).

A materialidade supracitada produz efeitos de sentido cuja construção está associada ao desejo de fusão e reciprocidade amorosa. O enunciado "não é só amor de fã" denota um desejo de ser amado, não nos moldes fraternos e "sagrados" da fama, mas no modelo romântico burguês. Neste caso, o fã alimenta o desejo de ser o parceiro/a do seu ídolo. Esse 
desejo tende a torná-lo apensas mais um no meio da multidão, porque deveras são muitos os que desejam ser o fã número 01 ou mesmo “o grande amor” da vida de seu ídolo.

Nessa relação, o desejo fusional é bastante evidente. O desejo é tamanho que o fã fascinado almeja saciar-se ao receber "pelo menos um abraço". É interessante perceber o (re)conhecimento da assimetria amorosa, tendo em vista que ao mesmo tempo em que imagina-se fundido ao ídolo, o fã reconhece a impossibilidade de trocas afetivas e amorosas mais intimas, desejando "pelo menos um abraço", já que não pode "ganhar um beijo na bochecha". A escrita dos fãs aproxima-se de uma escrita de si-para-si e também de si-para-ooutro, pois eles escrevem para externar seus desejos e emoções (uma escrita para-si) ao mesmo tempo em que escreve na esperança de ser correspondido pelo ídolo, isso é bastante evidente nas formações discursivas construídas em torno de enunciados apelativos: "amo, vocês, Restart, vocês são lindos! (FÃ 01); "Luan Santana, eu te amo mais que tudo" (FÃ 02); “amo você, Pelanza" (FÃ 03), "Restart eu amo vcss - Te Amo - Te Amo- Te Amo- Te AmoTe Amo" (FÃ 04). Dessa forma, o fã escreve com um desejo de ser ouvido, como se suas palavras ecoassem pelas redes sociais em direção ao seu ídolo.

Ao tratar das emoções nas relações fã/ídolo, Coelho (1999) escreve que as experiências de afeto construídas a partir dessa interação se dá como forma de "estado fusional", como se tais emoções propiciassem ao sujeito um afastamento de si ao mesmo tempo em que se perde na adoração do outro. Segundo Rezende e Coelho (2010, p.31), tais emoções compensariam "as incertezas do eu, permitindo a eclosão de uma sensação de êxtase. Amor e carisma teriam assim em comum a capacidade de provocar no indivíduo enamorado/fascinado uma sensação de conforto gerada pela 'fusão' com o outro”.

O desejo de fusão é bastante evidente no enunciado: "Quando você ama uma banda, você se torna parte dela!" (FÃ 05). A construção "você torna-se parte dela" nos remete ao desejo de fusão que está associado, não só ao desejo sexual, mas aquilo que Freud (1976) denomina de catexias, vocábulo usado para definir a intensidade das pulsões da energia psíquica. Segundo Freud (1976) o indivíduo busca fundir-se com aquilo que deseja, mesmo quando tal objeto lhe causa dor, afinal, o "outro é traumatizante” (FREUD, 1976). Tornar-se parte, neste contexto, é comungar da sua existência, dividir as alegrias, tristezas e infelicidades, é compartilhar as vitórias, amor e afeto, é dividir uma vida.

Coelho (1999, p. 61) escreve que "consciente de sua condição anônima, o fã lança mão de inúmeros recursos para transcendê-la, desta forma enredando-se em um dilema entre a consciência do seu anonimato e a certeza de sua singularidade.” Diante dessa problemática, o desejo de singularização tende a delinear-se de duas formas. Em alguns fãs essa característica 
se intensifica, em outros se atrofia. Isso se deve a fatores diversos que estão diretamente associados ao próprio processo de formação de subjetividades e, portanto, às experiências.

Por conseguinte, se o indivíduo/fã recebe estímulos diferentes e de formas diferentes, o que muitas vezes passa despercebido aos olhos de alguns pode ser visto como uma declaração de amor aos olhos de outro. Quanto mais ele se vê envolvido nas tramas midiáticas da Indústria Cultural, maior será o desejo de singularizar-se e de reciprocidade amorosa. Enquanto alguns mantêm a noção de pessoalidade, cultivando uma relação apenas de sacralização, outros se fascinam ao ponto de se entregarem ao amor, à paixão e ao desejo, mesmo sabendo que esse caminho corresponde a uma busca assimétrica por amor.

\section{CONSIDERAÇÕES FINAIS}

Neste trabalho propomos entender entender como os fãs utilizam a escrita de si como mecanismo de sacralização, através do qual também perpassa a exteriorização de suas emoções nas quais podem ser percebidos traços de subjetividade e identidade inerentes à condição de fã. A partir da Análise do Discurso, propomos a análise das materialidades textuais de um Diário de fã.

Endossando os resultados de pesquisas anteriores como Bussab (2004), Coelho (1999), Vieira (2015), Vieira e Paiva (2015) a relação entre fã/ídolo está ligada a um forte desejo de singularização, e ao desejo de fusão em que se distinguem dois tipos de emoções: o carisma/adoração e fascínio. O carisma apresenta-se como um forma de afeto ligado à adoração, assumindo caráter extremamente ritualístico, o que o aproxima dos ritos religiosos. Nesse caso, os ídolos são associados à deuses, a seres de grande perfeição física e espiritual. Por sua vez, o fascínio pode ser compreendido como uma experiência de adoração bastante conflituosa, pois ao mesmo tempo em que o ídolo é sacralizado (entenda, tornar sagrado) também é desejado amorosa e sexualmente.

Observamos o uso da escrita de si como forma de exteriorização de suas emoções, buscando através dela a produção de uma declaração de amor singular que se manifesta ora como adoração/carisma, ora como fascínio. Tais enunciados estão ligados ao desejo de fusão, ao sentimento de singularização e à imaginação simbólica que liga o anonimato do fã ao desejo de reciprocidade amorosa.

Nesse sentido, a escrita de si no Diário de fã configura-se como mecanismo discursivo através do qual os fãs exteriorizam as suas angustias, desejos e fantasias. O Diário de fã é o lugar de encontro. Nele os fãs podem expressar emoções marginalizadas em outros 
espaços sociais. Nele, o fã escreve sobre um entendimento de si e sobre um entendimento coletivo (uma escrita de si para si e de uma escrita de si para o outro), pois eles escrevem sobre suas experiências afetivas pessoais ao mesmo tempo que procuram um espaço junto às experiências do outro, sendo evidente a busca e a construção de um sentimento de pertença.

Os resultados da nossa pesquisa apontam, portanto, para duas conclusões (ainda que iniciais). A primeira refere-se a forma através da qual a Indústria Cultural influencia no processo de formação de subjetividades e construção da identidade dos público consumidor de "bens" culturais, sendo evidente à interferência dos ídolos no processo de constituição do sujeito/fã. A segunda refere-se a necessidade de construção de um conhecimento científico, discursivo, sociológico, antropológico etc., sobre as diversas literaturas manifestações e relações em torno da fan culture fenômeno ainda pouco discutido no Brasil. 


\section{REFERÊECIAS:}

BAUMAN, Zygmunt. Identidade. Tradução de Carlos Alberto Medeiros. Rio de Janeiro: Jorge Zahar, 2005.

BUSSAB, Mariana de Oliveira. A Celebridade e Seus Fãs: contribuição ao estudo das comunidades de marca no setor do entretenimento da Fundação Getúlio Vargas. 2000. 191 f. Dissertação (Mestrado em Administração de Empresas) - EAESP, Fundação Getúlio Vargas, São Paulo, 2004.

BLOG DO PLANETA. Declare seu amor por uma atração do Planeta no Diário de Fã. Disponível em:< http://wp.clicrbs.com.br/onossomundo/2011/01/25/declare-seu-amor-poruma-atracao-do-planeta-no-diario-de fa/?topo=52,1,1,199,e199\&status=encerrado $>$. Acesso em 10 de Jan. 2014.

BOURDIEU, Pierre. Coisas Ditas. São Paulo: Editora Brasiliense, 1990.

Esboço de uma Teoria da Prática. In: ORTIZ, Renato (Org.). A sociologia de Pierre Bourdieu. São Paulo: Editora Ática, 1994.

COELHO, M. C. P. A experiência da fama: individualismo e comunicação de massa. Rio de Janeiro: Editora FGV, 1999.

DORNELLES, Jonatas. Vida na rede: uma análise antropológica da virtualidade. Tese de doutorado. Porto Alegre/RS, 2008.

DURAND, Gilbert. A imaginação simbólica. São Paulo: Cultrix, 1988.

FOUCAULT, M. A escrita de si. In: O que é um autor? Trad. António F. Cascais e Eduardo Cordeiro. Lisboa: Passagens, 1992.

GOFFMAN, Erving. A representação do eu na vida cotidiana. Tradução de Maria Célia Santos Raposo. Petropólis: Vozes, 2011.

FREUD, S. O mal-estar na civilização. Rio de Janeiro: Imago, 1976.

JENKINS, Henry. Textual poachers: television fans e participatory culture. New York: Routledge, 1992.

LÉVY, Pierre. A inteligência coletiva: por uma antropologia do ciberespaço. São Paulo: Loyola, 2000.

Cibercultura. Rio de Janeiro: Editora 34, 1999.

MORIN, Edgar. Cultura de massas no século XX: neurose. Rio de Janeiro: Forense Universitária, 1997.

REZENDE, Claudia Barcellos; COELHO, Maria Claudia. Antropologia das emoções. Rio de Janeiro: Editora FGV, 2010. 
VIEIRA. Demóstenes Dantas. A Relação Fã/Ídolo, o Forró Eletrônico e a Distinção

Social: Discurso, Emoção e Identidade. 2015. 122f. Dissertação de Mestrado. Programa de Pós-Graduação em Ciências Sociais e Humanas - PPGCISH. Universidade do Estado do Rio Grande do Norte - UERN 2015.

VIEIRA, Demóstenes Dantas; PAIVA, Maria Soberana de. A Relação Fã/Ídolo e o Desejo de Fusão: uma Leitura dos Processos de Subjetivação a partir das Emoções. Revista Luminária. v.17 n.01 p. 50-65 jan/jun de 2015. 